\title{
BRITISH JOURNAL OF
}

\section{ANAESTHETIC \& RECOVERY NURSING}

\section{CONTENTS}

FROM THE CHAIRMAN

- New Year Resolutions

Manda Dunne

EDITORIAL

- Help Wanted!

Jessica Inch

\section{EDUCATION}

- Patient Consent, the Anaesthetic Nurse and the Peri-operative Environment: Irish Law and Informed Consent

Brenda Daly
ORIGINAL ARTICLE

- Regional Anaesthesia versus General Anaesthesia in Endovascular Aneurysm Repair: The Surgical Nursing Interventions

T. Fotis, A. Mitsos, T. Perdikides, E. Lambrinou,

E. Konstantinou

INTERVIEW

- Your Local Anaesthetic/Recovery Unit: What Makes it Special?

Suzanne Tyne

15

3 NOTES TO AUTHORS 
https://doi.org/10.1017/S1742645609000412 Published online by Cambridge University Press 